\title{
Real Time Control Strategy for Hybrid Electric Vehicles
}

\author{
Professor Dr. Sorush Niknamian \\ Board Member of Weston A Price Foundation, Washington DC, USA
}

\begin{abstract}
Based on the complex structure of electric hybrid car and uncertainty in driving force structure of electric hybrid car, different strategies have been presented for optimal management of energy based on smart methods. In this study by the decision making nature of fuzz logic, a movement map for Parallel Hybrid Electric Vehicle (PHEV) is made based on the required path. In a parallel hybrid car, recharging control of battery and auxiliary torque of electric engine are used as the key points of movement. Based on the disadvantages of pure electric car, to increase the life of battery and its easy use, we need a movement strategy balancing the battery charge for a movement path. If the battery is charged at no load by the combustion engine, NOx emission is increased and the battery charge is not good and adequate for HEV performance under no-load condition by the energy retrieval power and combustion engine. For a movement structure, it is hard to define the conversion point between the motor performance and generator performance exactly. By a drive strategy based on crisp methods, the battery charge is sensitive to the moving samples of driver, path condition and load conditions. Using fuzzy control strategy to control varied non-linear systems is very suitable and it is robust against the changes of components of sub-systems and inexact measurements. New York City Cycle (NYCC) is considered to perform simulation. As shown in paper, the fuzzy control strategy can keep the charge stage of batteries at good range
\end{abstract}

Keywords: Fuzzy Control Strategy, Hybrid Electric Vehicles, supervisory control strategy, Hybrid System, Switching Strategy.

\section{Introduction}

The control strategy in hybrid cars is an algorithm by which the energy is generated, stored and consumed. The control strategies are designed to achieve some simultaneous goals. The goa of these strategies is reducing fuel consumption and pollutants and maintaining or increasing the functional capabilities of car as increasing acceleration and slope paths. Different types of control strategies are introduced for hybrid cars [1]. Due to the complex nature of hybrid cars, the designed control strategies based on engineering attitude don't provide the optimal performance of car and using optimization algorithms to achieve an optimal control strategy is necessary. The present study applies simulation based on fuzzy logic to design the controller system of parallel electric hybrid cars.

As there is little practical experience in construction and making the low hybrid electric cars and their hardware is costly, it is suitable to use math modelling and computer simulation techniques to evaluate the initial designs and different aspects of task. In modelling and 
simulation of cars, there are two different approaches as facing-backward and forward-facing [2].

In the present study, facing-backward method is applied. The simulations using facingbackward method respond this question, if it is assumed that the car takes the required path, how does each part of card power chain works? In this method, there is no need to the driver model and the required force is calculated for acceleration of car during the time directly from the required speed (as planned based on the driving cycle) during the path. Then, the required force is converted to the moment as provided by the upstream component and the linear speed of car is converted into the required rotational speed. Stage by stage of these computations is continued inside the car power chain as backward, opposite to the running power, in order to calculate the consumed fuel or electric energy to drive. Facing-backward method is suitable as it is corresponding to the dynamometer tests of chassis. These tests are standard one being used to evaluate the fuel consumption and pollutants of cars [3].

Among the introduced structures for hybrid cars, parallel structure is suitable. The control strategy of parallel hybrid cars determines that how the required moment of the driver is distributed among combustion engine, electric engine and brakes. For the negative required moments, the sum of electric engine moments and brake should be equal to the required moment of the driver. For the positive moments, the sum of moments of combustion engine and electric engine should be equal to the required moment of driver. There are different control strategies for parallel hybrid cars among which, control strategy of electric aid is much more applied. The control strategies of hybrid cars are designed to achieve some purposes simultaneously. These goals include reduction of fuel consumption, mitigation of pollutants of exhaust and improvement of functional features of car such as accelerating and slope. Thus, the problem of the design of controller of hybrid cars is a multi-purpose optimization problem [4].

\section{Review of literature}

Demirli K, Khoshnejad M (2009, a neuro-fuzzy model has been developed for autonomous parallel parking of a car-like mobile robot. In the approach they have focused on the most difficult case of parallel parking which is the case when the parking space dimensions cannot be identified. The proposed model uses the data from three sonar sensors mounted in the front left corner of the car to decide on the turning angle. Fifth-order polynomial reference paths for three different size parking dimensions have been used to generate the training data. The fuzzy model has been identified by subtractive clustering algorithm and trained by ANFIS. The simulation results show that the model can successfully decide about the motion direction at each sampling time without knowing the parking space width, based on the direct sonar readings which serve as inputs. The results which are based on real dimensions of a typical car demonstrate the feasibility and effectiveness of the proposed controller in parallel parking [21]. 
Montazeri-Gh M, Mahmoodi-k M (2015) in a study stated that reduction of greenhouse gas emission and fuel consumption as one of the main goals of automotive industry leading to the development hybrid vehicles. The objective of this paper is to investigate the energy management system and control strategies effect on fuel consumption, air pollution and performance of hybrid vehicles in various driving cycles. In order to simulate the hybrid vehicle, the combined feedback-feedforward architecture of the power-split hybrid electric vehicle based on Toyota Prius configuration is modeled, together with necessary dynamic features of subsystem or components in advisor. Multi input fuzzy logic controller developed for energy management controller to improve the fuel economy of a power-split hybrid electric vehicle with contrast to conventional Toyota Prius Hybrid rule-based controller. Then, effects of battery's initial state of charge, driving cycles and road grade investigated on hybrid vehicle performance to evaluate fuel consumption and pollution emissions. The simulation results represent the effectiveness and applicability of the proposed control strategy. Also, results indicate that proposed controller is reduced fuel consumption in real and modal driving cycles about $21 \%$ and $6 \%$ respectively [24].

Zabibhi (2016) stated that with the growth of modern community, the increase of vehicles and shortage of fossil fuels, environmental pollution in recent years, based on the energy resources use and reduced dependence on fossil fuels, using hybrid car is much prevalent. Generally, hybrid electric cars are those using more than on power sources in driving. Automotive mostly compete about the design of control system of these cars. Thus, the thesis investigated and designed control strategy to manage energy. The method of using driving cycles in energy management is of great importance. Most of the researches in energy management are with definite cycles but we don't have these cycles in real conditions. At first we identify the driving cycles using LVQ neural network. For these 4 cycles including the different road conditions, the features are extracted from these driving cycles, by the indefinite driving cycle features and using DCR algorithm, we classify indefinite driving cycle. Then, we design the control strategies. In the first stage, we design control strategy with definite cycle by fuzzy controller. Finally, we considered control strategy based on indefinite cycle and its optimization with ants algorithm. The proposed strategies include some control techniques to take some steps to develop this model of cars as the energy requirements are met as reduction of fuel and battery level is acceptable and pollution is also reduced. The applied car in the thesis was selected as series [17]. 
Najfi et al., (2017) stated that plug-in electric hybrid cars were electric hybrid cars being charged by connecting to electricity. Plug-in cars can work in electric mode or a combination of batter and internal engine. Energy management is an important issue in these cars as their performance is affected considerably. Thus, the design of a good control method is of great importance. The dynamic planning is an off-line optimization method giving the optimal solution to us. However, high computation volume has made its online application impossible. The strategies based on rules can be used as a method in online applications. As the hybrid driving force system is non-linear and varied over time, fuzzy logic is the best method to solve the reduction of fuel consumption in these cars. This method doesn't present an optimized solution. This paper didn't apply a dynamic planning to determine the fuzzy controller rules. The parameter of electric engine efficiency as one of the inputs of fuzzy system eliminates the dependency of method on special driving cycle. The strategy aimed to reduce the fuel consumption in al driving cycles. The proposed strategy was simulated on the assumed car and was compared with the results of simulation of dynamic planning [18].

\section{Modelling engine [1]}

Based on the complexity of driving force system of electric hybrid car, various strategies have been designed based on fuzzy logic to manage energy. Based on decision making of fuzzy logic and its robustness against the turmoil such as road conditions and existing uncertainties in the driving force, it is used to design a strategy of real time control to optimize the system performance based on the system instantaneous conditions. Using fuzzy control strategy to control varied non-linear systems is very suitable and it is robust against the changes of components of sub-systems and inexact measurements. This part deals with the design of a control strategy using stateflow tool box and then the energy management strategy is designed based on fuzzy logic using Fuzzy environment for parallel electric hybrid cars based on advisor models. 


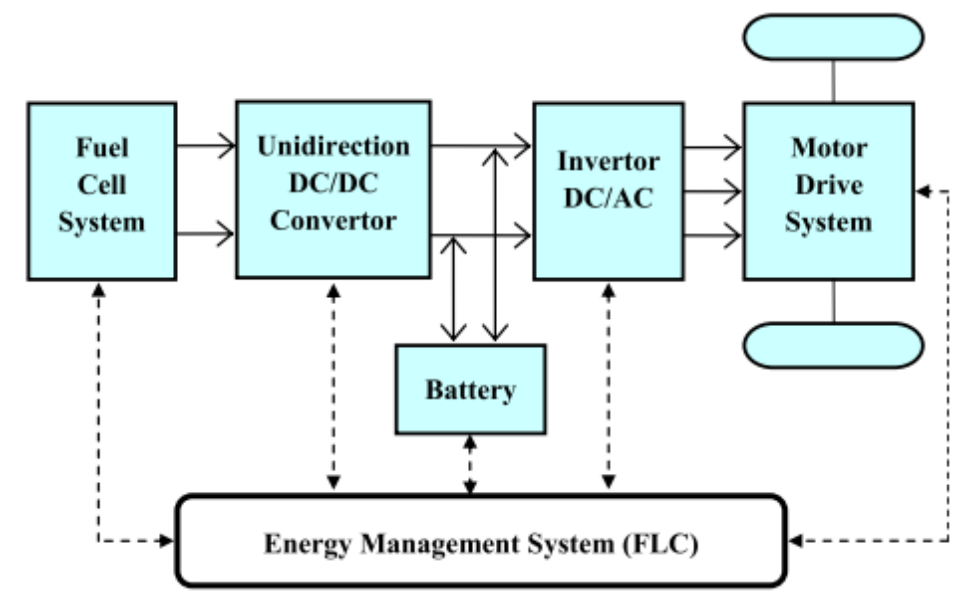

1 The design of smart supervisory control strategy based on fuzzy logic for parallel hybrid car

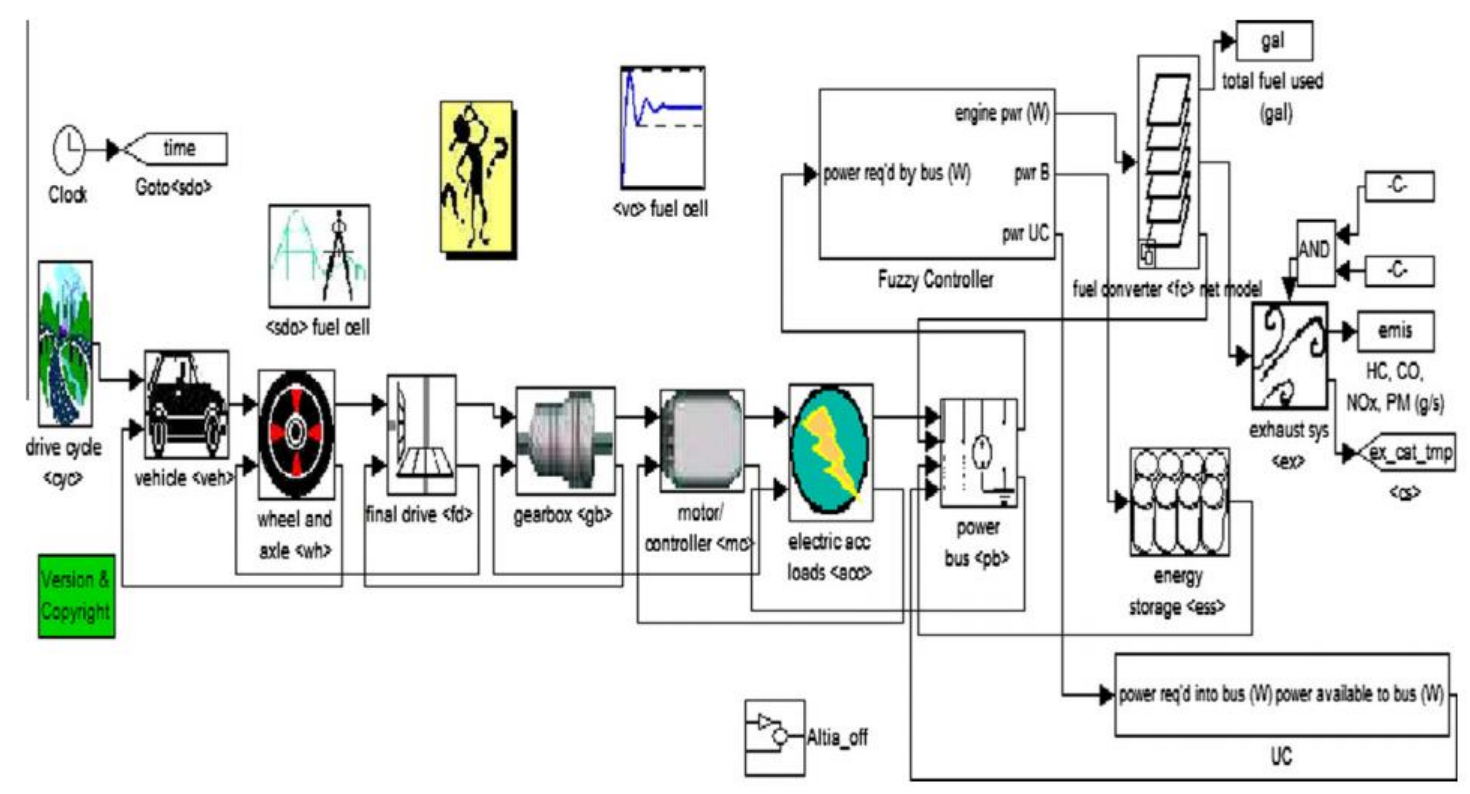

In reference [5], most of the modellings used in Advisor software is based on static and quasistatic models. The models used in this software are mostly based on the optimized maps and tables. The structure of existing parallel hybrid car in Advisor software is as shown in Figure (2).

\section{High level supervisory controller}

The supervisory controller is used to determine the performance modes of electric hybrid cars. Indeed, high level supervisory control controller defines when the combustion engine should be on and when the combustion engine should be off. To do this, all the required conditions for being on and off are investigated: 
Condition 1) As the combustion engine should work in maximum efficiency region, if the vehicle speed is lower than limit, the combustion engine should be off. This definite limit in Advisor software is as cs_electric_launch_spd. If the car speed is below this value, the hybrid car is driven as an electric car and the pollution is zero.

Condition 2) If the battery charge state is above minimum and the car speed is lower than the minimum value in condition 1 , the combustion engine is again turned off.

Condition 3: If the demanded torque is higher than the threshold torque and the car speed is higher than its minimum limit, the combustion engine is turned on.

$$
\mathrm{T}_{\text {th }}=\text { cs_off_trq_frac } \times \mathrm{T}_{\text {eng_max }}
$$

Where, $T_{\text {eng_max }}$ is the torque of combustion engine is maximum in efficiency area and cs_off_trq_frac as a value is ranging zero and one.

Condition 4) If the demanded power is higher than the maximum battery power, the combustion engine is turned on.

Condition 5) If the demanded torque is lower than the threshold torque and the combustion engine temperature is lower than its maximum level and the battery charge state is higher than its minimum value, the combustion engine is turned off. Maximum allowed temperature for combustion engine is $81.6^{\circ} \mathrm{C}$.

Condition 6) If the temperature of combustion engine is lower than its maximum level and combustion engine is on already, the combustion engine is turned on as the combustion engine has high fuel consumption and low efficiency if the temperature of combustion engine is lower than its maximum level at lower temperature. If the combustion engine has been on already and the clutch is involved, the combustion engine is turned on.

To design the strategy of supervisory control, all the above conditions are implemented in Stateflow tool box and are as shown in Figure 3. 


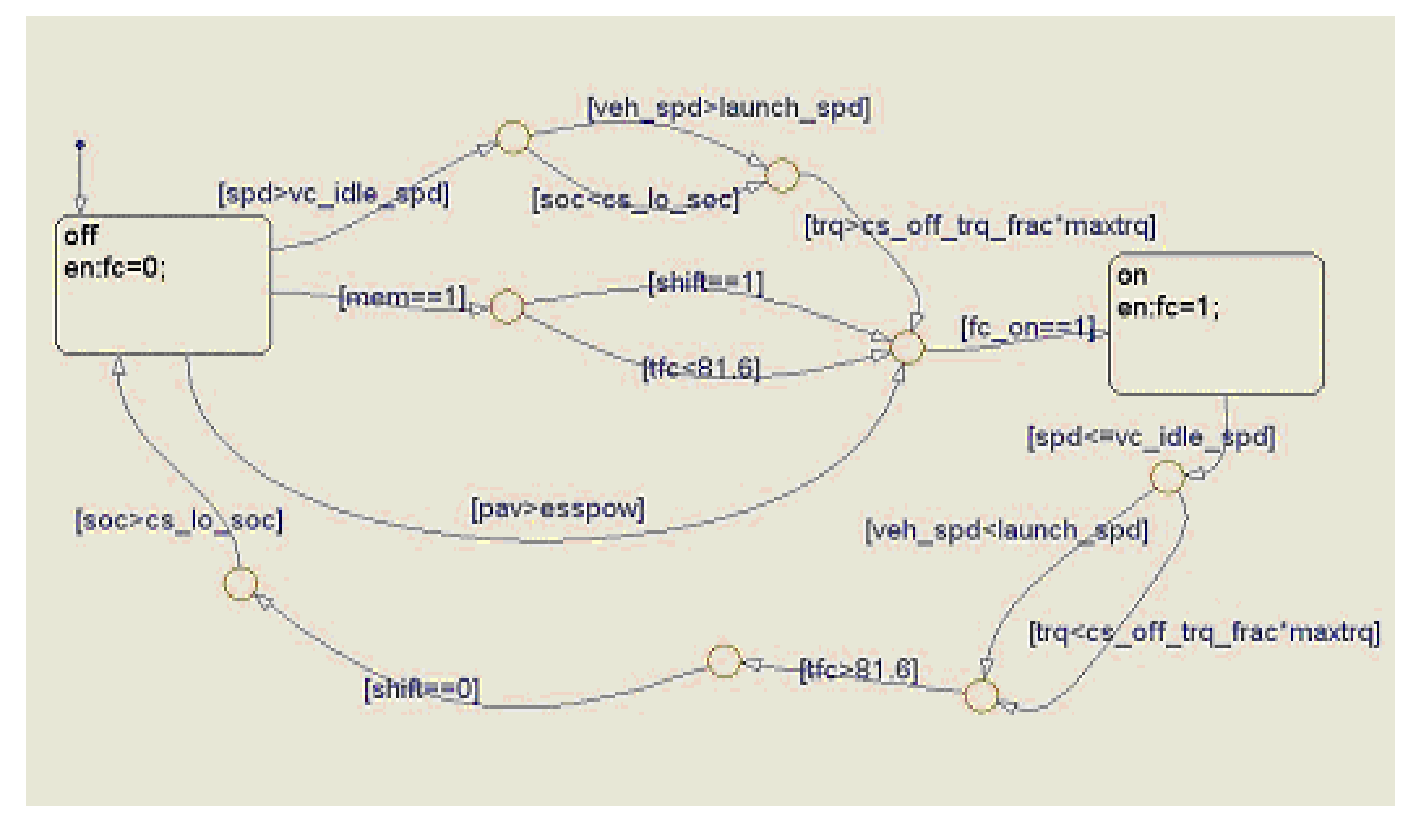

Figure 3 The structure of supervisory control is implemented in stateflow tool box.

The structure of high level supervisory controller strategy as implemented by Stateflow tool box in Simulink environment is illustrated in Figure 4.

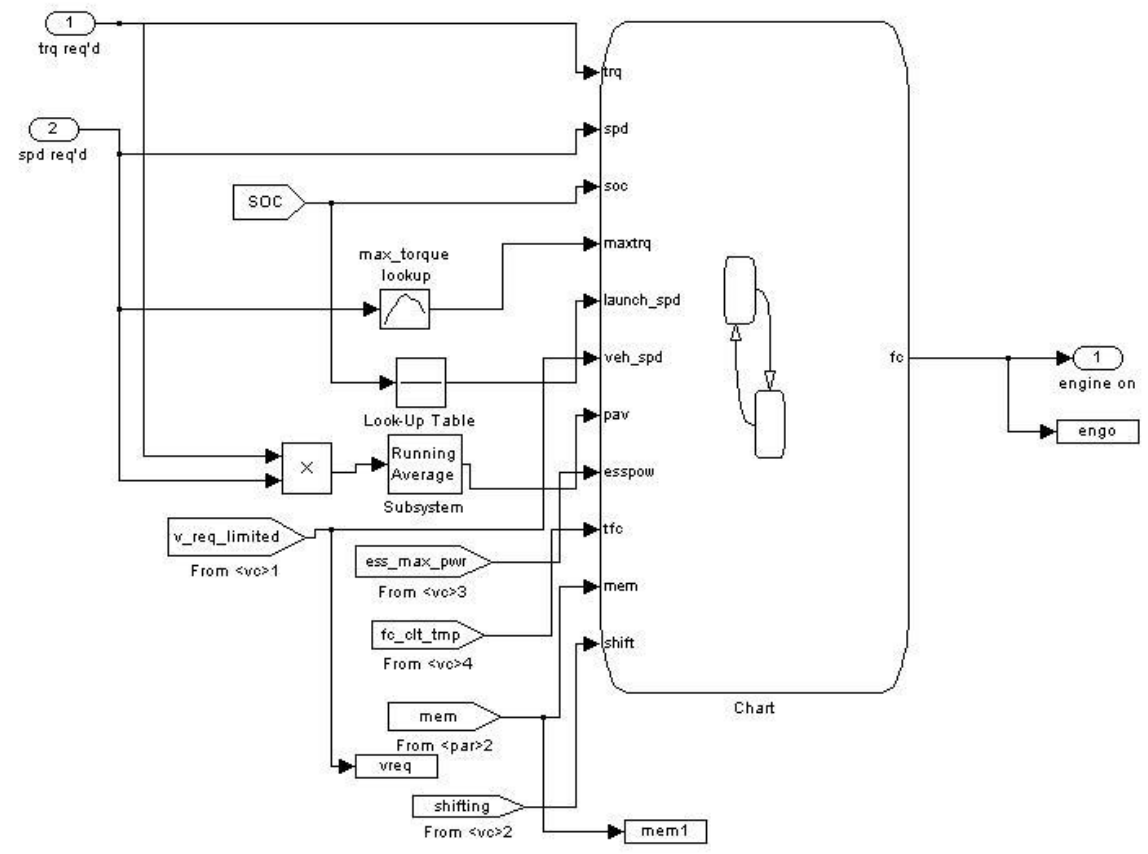

Figure 4 The high level control strategy and its implementation in Simulink environment 

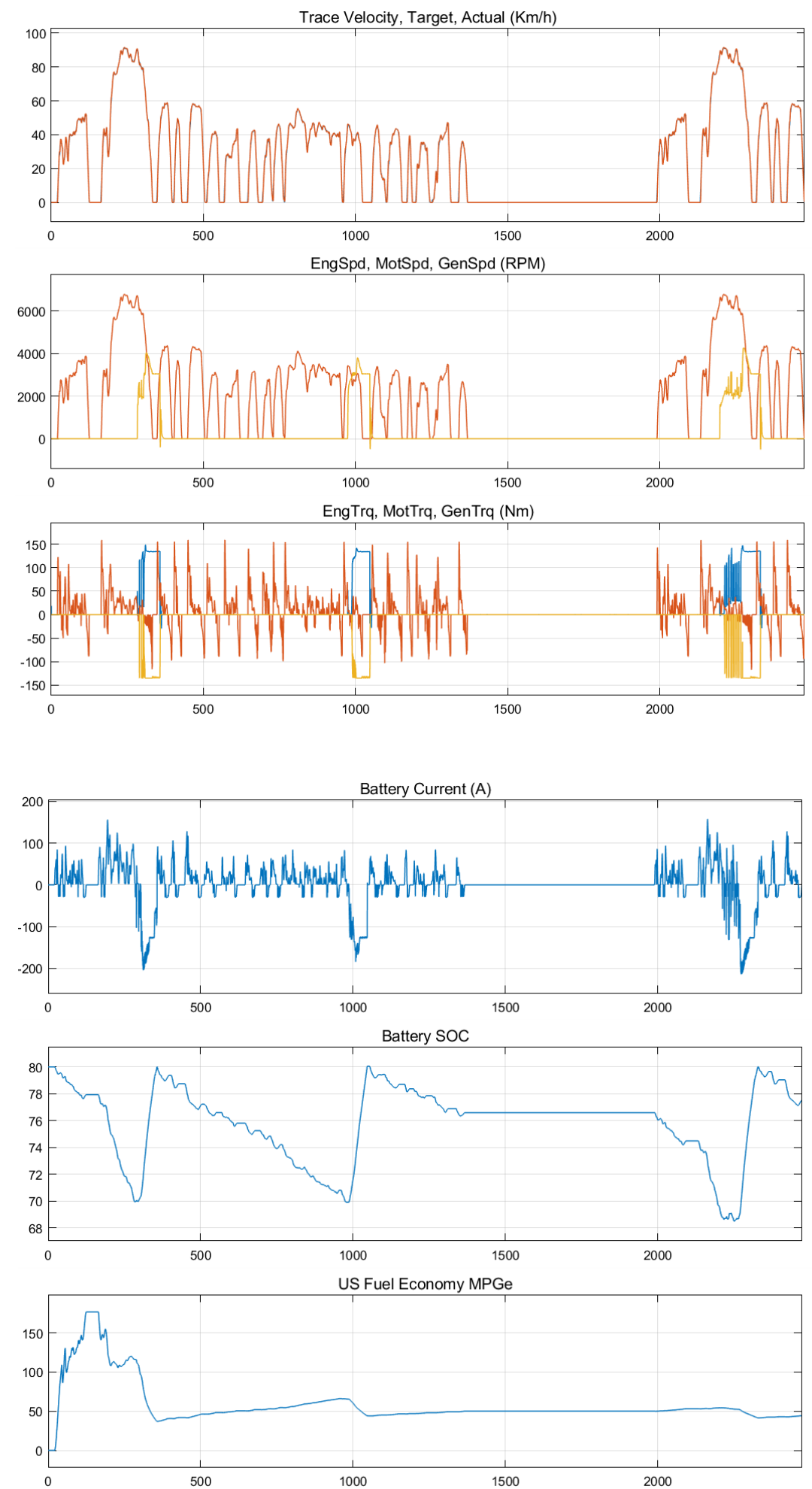

The optimization of energy management based on fuzz logic

In the second level of strategy of higher structure, the energy management strategy is located. In order to perform the power instantaneous division as optimally between the combustion engine and electric engine, a fuzzy control structure is applied. The fuzzy control strategy based on the demanded torque and charge state of batteries, tunes up the optimized torque of combustion engine and the remaining torque is provided via electric engine. 
Where, TLOAD is the demanded torque, TICE_Set optimized torque of combustion engine and TEM_Desired is the optimal torque for electric engine.
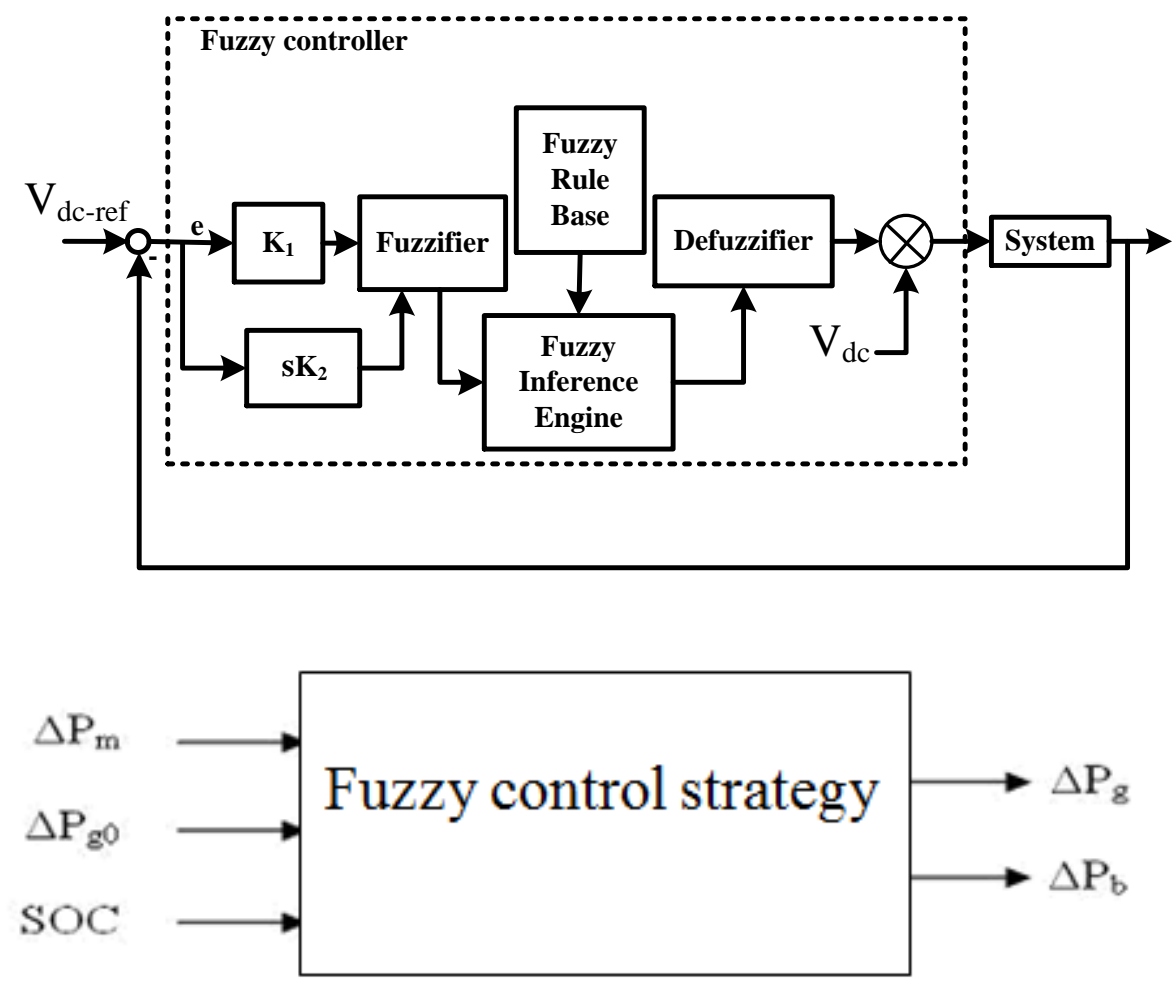

Figure 5 The general structure of fuzzy control strategy

The general fuzzy controller is consisted of the followings:

1) Scaling the input signals

2) Fuzzy controller

3) Scaling output signals

To design the fuzzy control strategy, the results of existing comparative control strategy in Advisor software are used as benchmark. The most important issue in the design of fuzzy control strategy is optima 1 tune up of membership function parameters and the rule bases. To do this, by Fuzzy Inference System in fuzzy toolbox, an optimal fuzzy controller is designed. 


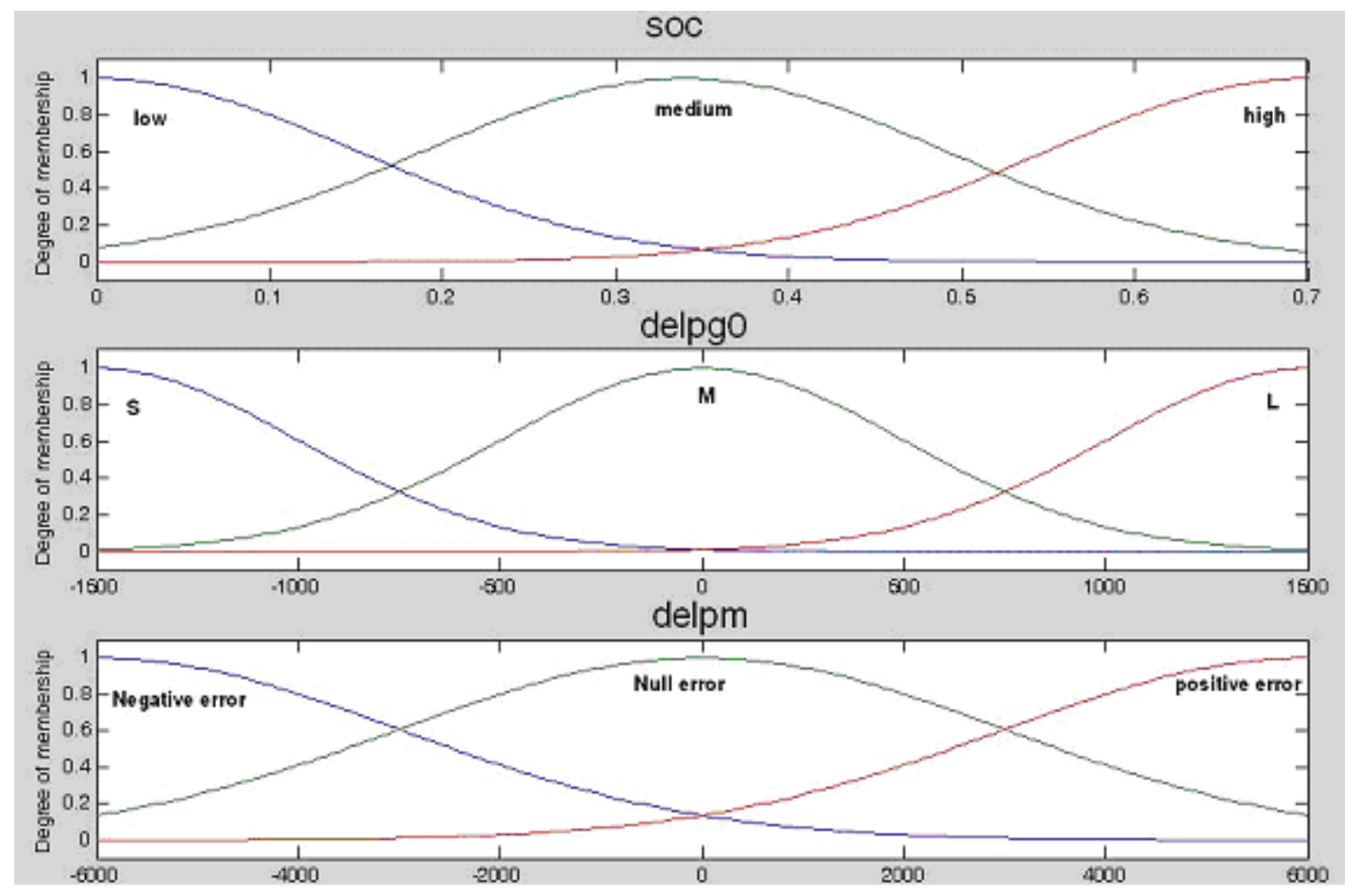

Figure 6 shows the input membership functions of fuzzy controller The fuzzy rules basis is shown in Table 1 .

Table 1 The fuzzy rules basis

\begin{tabular}{|c|c|c|c|c|}
\hline \multicolumn{5}{|c|}{ Low SOC } \\
\hline & & \multicolumn{3}{|c|}{$\Delta \mathrm{P}_{\mathrm{m}}$} \\
\hline & & $\mathrm{N}$ & $\mathrm{Z}$ & $\mathrm{P}$ \\
\hline \multirow{3}{*}{$\Delta \mathrm{P}_{\mathrm{g} 0}$} & $\mathrm{~N}$ & PM & PB & PVB \\
\hline & $\mathrm{Z}$ & PS & PM & $\mathrm{PB}$ \\
\hline & $\mathrm{P}$ & $\overline{A Z}$ & PS & $\mathrm{PM}$ \\
\hline \multicolumn{5}{|c|}{ Medium SOC } \\
\hline & & \multicolumn{3}{|c|}{$\Delta \mathrm{P}_{\mathrm{m}}$} \\
\hline & & $\mathrm{N}$ & $\mathrm{Z}$ & $\mathrm{P}$ \\
\hline \multirow{3}{*}{$\Delta \mathrm{P}_{\mathrm{g} 0}$} & $\mathrm{~N}$ & PS & PM & $\mathrm{PB}$ \\
\hline & $\mathrm{Z}$ & $\mathrm{AZ}$ & PS & PM \\
\hline & $\mathrm{P}$ & NS & $\mathrm{AZ}$ & PS \\
\hline
\end{tabular}




\begin{tabular}{|c|c|c|c|c|}
\hline \multicolumn{2}{|c|}{ High SOC } \\
\hline \multirow{2}{*}{} & \multicolumn{3}{c|}{$\Delta \mathrm{P}_{\mathrm{m}}$} \\
\cline { 3 - 5 } & $\mathrm{N}$ & $\mathrm{N}$ & $\mathrm{Z}$ & $\mathrm{P}$ \\
\hline \multirow{4}{*}{$\Delta \mathrm{P}_{\mathrm{g} 0}$} & $\mathrm{AZ}$ & $\mathrm{PS}$ & $\mathrm{PM}$ \\
\cline { 2 - 5 } & $\mathrm{Z}$ & $\mathrm{NS}$ & $\mathrm{AZ}$ & $\mathrm{PS}$ \\
\cline { 2 - 5 } & $\mathrm{P}$ & $\mathrm{NM}$ & $\mathrm{NS}$ & $\mathrm{AZ}$ \\
\hline
\end{tabular}

For example, if the charge state of batteries is low and $\Delta \mathrm{P}_{\mathrm{g} 0}$ is positive and $\Delta \mathrm{P}_{\mathrm{m}}$ is zero, the output is PS (positive small).

If the battery charge state is medium and $\Delta \mathrm{P}_{\mathrm{g} 0}$ is negative and $\Delta \mathrm{P}_{\mathrm{m}}$ positive, the output is positive big $(\mathrm{PB})$ 
The simulation results

The control strategy is based on the dynamic model of series hybrid car designed in Matlab environment. The simulation is performed on NYCC driving cycle. Figure 7 indicates the results of simulation.
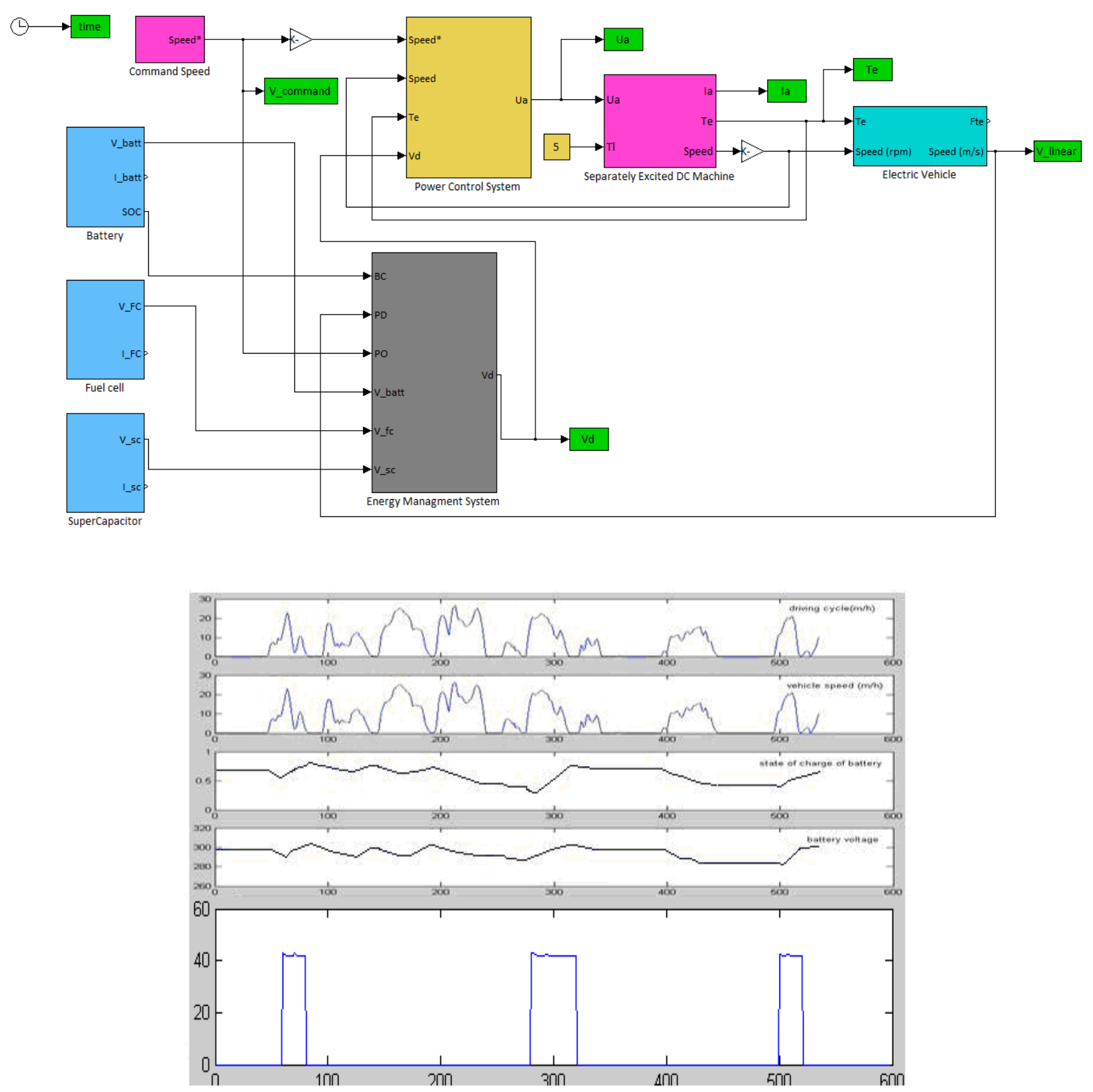
Figure 7 The simulation results of fuzzy control strategy based on dynamic modelling of subsystems

a. Driving cycle, $\mathrm{b}$ car speed, $\mathrm{c}$ battery charge state, $\mathrm{d}$ battery voltage e combustion engine power

As shown in Figure 7, the combustion engine power is in good range when it is on $42 \mathrm{KW}$ and the charge state of battery is increased when the combustion engine is one. The control strategy can keep the charge of batteries at good level. Other features of fuzzy control strategy are robustness against the driving cycle changes. As shown in the simulation results, the control strategy can keep the driving capability of car.

By the evaluation of control strategies in the first chapter, the control strategies based on optimal control theory are not implemented under the real conditions of driving as these strategies are mostly based on the driving cycles and the results are achieved as benchmark for other control strategies. The control strategy based on static optimization is based on static modelling of sub-systems.

To achieve a strategy of real time control, the control strategy decide based on current conditions and real conditions of hybrid car system and control strategy is not dependent upon the driving cycle conditions. Based on the hierarchy control structure in electric hybrid car and identification of control models and selection of good switching chain by which the system states are used to fulfill the system performance conditions as a set of discrete outcomes and we investigate the control strategy of real time for electric hybrid car. Here, by a Hybrid Dynamical Control for a driving outcome system, the control strategy is designed. The optima real time control strategy doesn't mean that it is attempted that the global efficiency of system is maximized and to design the real time control strategy, at first the trend line of system is divided into small parts and each section is corresponding to a performance region. Then, the optimization is performed on each performance region being used to minimize the objective function. Thus, control commands here are not absolute optima and they are sub-optimal. Such strategies are practical and in such strategy, we don't need a pre-defined cycle.

The possible strategies for control system are as follows:

1- Providing the required torque by combustion engine alone

2- Providing the required torque by electric engine alone

3- Using combustion engine for driving electric motor as a generator of battery charge and using the remaining of torque of combustion engine for driving cars.

4- In braking, using the energy retrieving of brake for charging the batteries as the electric motor is driven by electric motor and acts as a generator.

5- Providing the required torque by the electric and combustion motors

In case 5 , instead of using a state, we use the limited set of states. To do this, power division problem is divided into three groups:

Power divisions as $25 / 75,50 / 50,75 / 25$ to divide power between electric motor and combustion motor can be considered. 
Indeed, each of power division strategies has different result for different inputs for driving resources, electric motor and combustion motor.

For optimal distribution of power, efficiency curves of each of components are used. Figure 8 shows the efficiency curves of combustion engine of sample as it is used as sample. The curve shown by arrow indicates the operating points in which combustion engine has the maximum efficiency. Thus, the combustion engine point should be in this region.

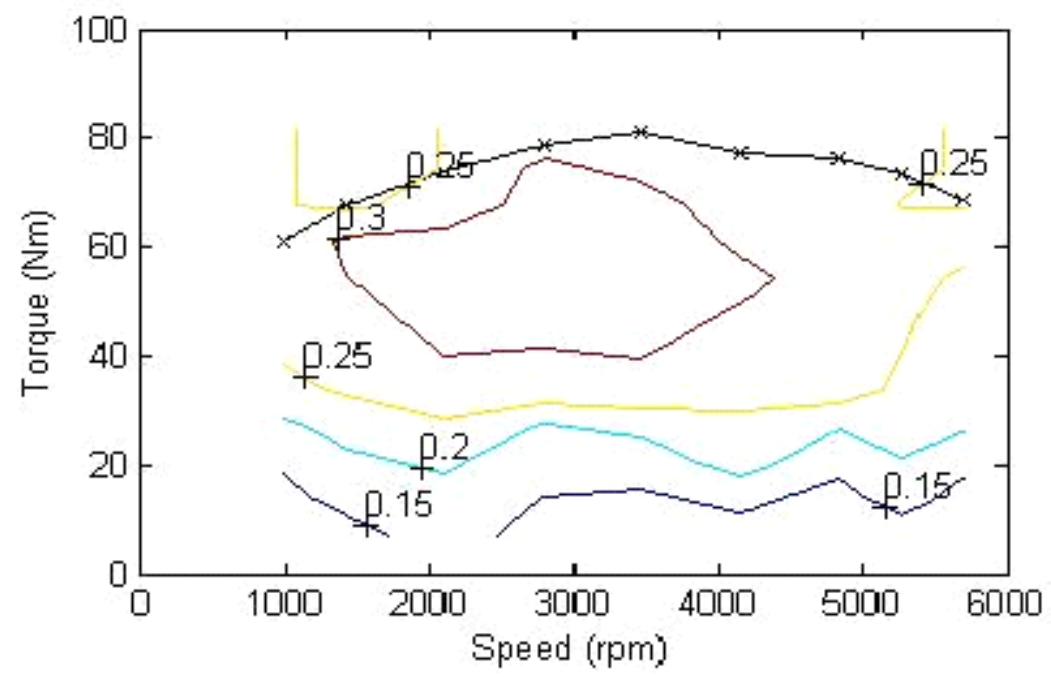

Figure 8 The optimal operating points and combustion engine efficiency curve

Also, Figure 9 is the curve of electronic motor efficiency. Here, the curve being shown by arrow indicates the operating points in which electric motor efficiency is maximum.

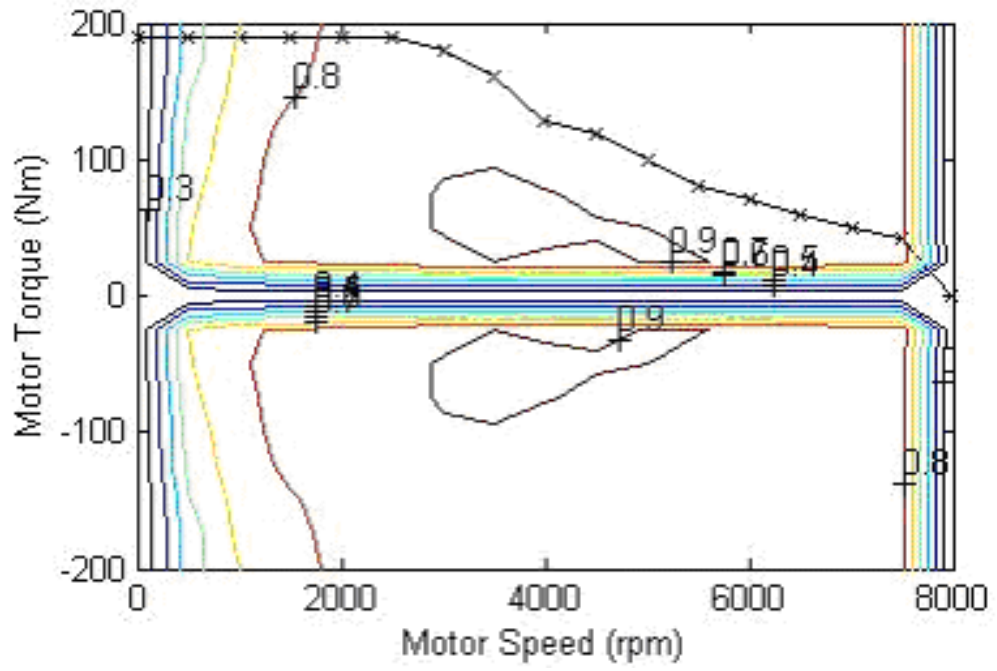

Figure 9 The optimal operating points and curve of electric motor efficiency

In order that the battery works in the maximum efficiency region, its charge level should be ranging $0.5,0.8$. Figure $5-3$ shows the curve of battery maximum efficiency. 


\section{Conclusion}

1- Until now, various control algorithms are presented for optimal energy management in electric hybrid cars. Most of these methods are based on the algorithms of optimal control and the like. These methods due to its high calculation volume are not implemented under real conditions of movement as the future of movement is not clear for us. Thus, we should design a controller for hybrid car system to select an optimal performance based on the real conditions of system. A real time control strategy should be as the system performance is optimized locally at any time and on the other hand, it should have structural simplicity. Thus, we need a hierarchy control structure for hybrid cars. As shown in the results of simulation, the designed control strategy is not dependent upon the pre-defined movement cycle and it can select the optimal performance mode in the mode system and the related changes and real time is suitable for a control strategy.

2- Other features of the strategy of required control is keeping the battery charge state at good level and this doesn't reduce the battery charge considerably. By dividing the performance region of control strategy, the batteries are charged during the system performance in some states.

3- By dividing the system performance path, the problem of combustion engine function in maximum efficiency regions is removed. When the combustion engine works in the maximum efficiency region, this increases fuel consumption due to the engine function at high torques. But in this state, due to the existing conditions in system, the combustion engine is switched to the other performance modes in some states and this transfers the generating torque to the lower levels and fuel consumption is reduced.

4- In the complex systems, other conditions are added to the supervisory controller, such as the effect of combustion engine temperature and this is one of the important features of supervisory hierarchy control structure.

\section{References}

[1] B. Mashadi, B. A. Emadi, Dual-Mode Power- Split Transmission for Hybrid Electric Vehicles, IEEE Trans. On VEHICULAR TECHNOLOGY, vol. ॰9, no. ₹, Sep. ץ. ••

[2] Mehran Mazandarani, Ali Vahidian Kamyad , Naser Pariz, Fuzzy Optimal Control under Generalized Differentiability of Fuzzy-number-valued Functions, $\Sigma$ PthP International Conference of Iranian Operations Research Society, $r \cdot 11$.

[3] N. J. Schouten, M. A. Salman, N. A. Kheir, Fuzzy Logic Control for Parallel Hybrid Vehicles, IEEE Trans. On Control Systems Technology, Vol. '•, NO. r, May r.. r.

[4] J. Balakrishnan, Indulal. S., Adaptive Neuro-Fuzzy Control of Internal Combustion Engine for Hybrid Electric Vehicle, $1 \cdot$ PthP National Conference on Technological Trends

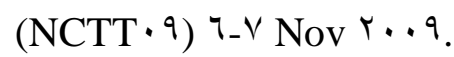


[5] National Renewable Energy Laboratory, ADVISOR Documentation, r. April, r..r.

[6] Xia MENG, N. LANGLOIS, Optimized Fuzzy Logic Control Strategy of Hybrid Vehicles Using ADVISOR, International Conference on Computer, Mechatronics, Control and Electronic Engineering (CMCE), r. $\cdot \bullet$

[7] Ali Mohammadi, Seyed Mohammad, Mohammadian. Mohsen Zabihi Behzad, Analysis and Review of Strategies and Provide Control Strategy in Energy Management on Hybrid Electric Vehicles, 2016.

[8] Najafi, Nazila, Rahmani Zahra, Hassanzadeh.Mojtaba, Fuzzy logic based energy management strategy to reduce fuel consumption in in-plug electric hybrid vehicles, 2017.

[9] Najaran, Samiya, Rahmani Zahra, Hasanzadeh, Mojtabi, Smart Energy Management Energy Management Strategy to Reduce Fuel Consumption in Electric Hybrid Electric Vehicles with Parallel structure, 2016.

[10] [Soleimani, Mehdi, Sobhani, Amir Hossein, Ismailiun, Abed, Designing an Intelligent Control Strategy to Reduce Fuel Consumption and Disclosures in Hybrid Electric Vehicles With Parallel Structure in Arak . Authors, 2015.

[11] Dawei M, Yu Z, Meilan Z, Risha N. Intelligent fuzzy energy management research for a uniaxial parallel hybrid electric vehicle. Computers \& Electrical Engineering. 2017 Feb $1 ; 58: 447-64$. 